\title{
Too long in the rain ... rural doctors get some relief
}

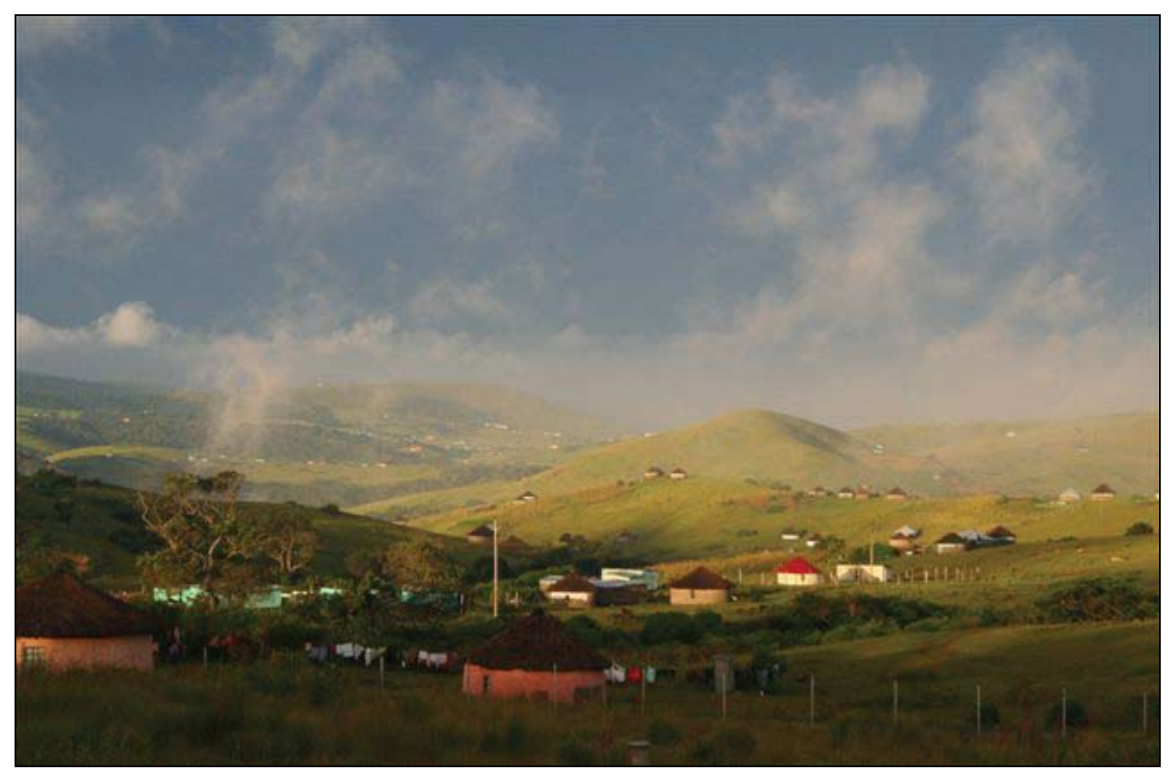

Clouds lifting at last? An Eastern Cape rural scene.

A long-awaited support programme for isolated, under-resourced rural doctors will start in the Eastern Cape this year once a 3-year, R19 million donation from the Clinton Foundation is finalised. The initiative has the full backing of the national and Eastern Cape provincial departments of health, and of the Rural Doctors Association of South Africa (RuDASA).

The main target group is private doctors doing sessions in small rural hospitals and clinics, but doctors and pharmacists working full time in these facilities will also benefit. The money will fund 'practice managers' or 'facilitators', initially in the muchneglected Ukhahlamba and Chris Hani districts. If the programme works well it will be extended in 2011 and 2012 to all the rural areas of the Eastern Cape, and the provincial government will start to pick up a portion of the costs.

The practice managers will organise much-needed Continuing Professional Development (CPD) sessions within the district at times that private GPs can attend and that are relevant to practice in remote and under-resourced areas. The practice managers will also trouble-shoot (e.g. help to resolve maddening issues such as non-payment of claims/allowances and repair of minor equipment), arrange locums and, if possible, facilitate on-site mentoring by (mostly) retired senior doctors. The facilitators will also spend $20 \%$ of their time offering these services to foreign doctors recruited by African Health Placements (AHP), the country's top recruitment and placement NGO.

Their job will be to regularly visit and get to know all doctors and health service managers working in small towns in their allocated district and becoming intimately acquainted with their unique challenges and needs. The project manager, Dr Tim Wilson, a former rural health senior staffer in the national health department (to which he now consults), is to spearhead the plan once negotiations between local stakeholders and the Clinton Foundation have been finalised.

\section{Greasing the wheels}

Wilson explained: 'Basically it's about addressing the professional isolation of rural practice and greasing the wheels of the machine so that ultimately rural doctors are happier and can get on with what they're trained to do in an environment that works for them'. This will benefit both their public and private patients. Initially, the CPD sessions will be held monthly in Aliwal
North, Queenstown and Mthatha, taking note of existing CPD activities and encouraging doctors to present cases for discussion to earn extra CPD points - mostly within about an hour's travel of their workplace.

Each of the project's practice managers will have a budget of R10 000 per month for spending on minor equipment and repairs that doctors have not yet been able to secure through normal channels with the proviso that the outcome facilitates better service delivery and does not replace the need for regular maintenance budgets.

The mentorship component - a bugbear for deep rural doctors for whom supervision is all too often a rare luxury - will test the creative and persuasive skills of the practice managers. They will have to persuade retired or 'down-scaling' veteran clinicians finally enjoying a muchanticipated rest to pitch in in return for their travelling costs plus a small basic fee.

\begin{tabular}{c}
\hline 'Basically it's about \\
addressing the professional \\
isolation of rural practice \\
and greasing the wheels \\
of the machine so that \\
ultimately rural doctors are \\
happier and can get on with \\
what they're trained to do.
\end{tabular}

The idea is to get the mentors to 'adopt' two district hospitals, spend half a day at each per month, establish good relations with the local doctors and the hospital managers, do ward rounds, discuss issues with staff and be available by telephone at 'reasonable' times. The mentors will be advisors, not managers, and will not cover hospitals visited regularly by one or more specialist doctors employed by the province. At the time of going to press, another idea was also to persuade a family practice specialist working at one hospital to spend 2 days a week 
visiting other hospitals in their district to provide clinical supervision and management, thus raising clinical standards. This specialist would work hand in glove with any local mentor recruits, except that, unlike them, they would perform a vital management role.

The two initial target districts are among the 18 'priority districts' identified nationally as most in need of upgrade and support, not least in advance of this year's expansion of HIV services and the implementation of the hotly debated National Health Insurance (NHI).

\begin{tabular}{c}
\hline 'If the red tape at Bhisho \\
(Head Office) is such that \\
it is too difficult for the \\
province to pay a doctor \\
working intermittently at \\
different district hospitals, \\
the AHP undertakes to \\
pay them from the project \\
budget'.
\end{tabular}

\section{Take a break, doc}

Another possibility is for locums, hugely sought after by many of the dedicated rural clinicians wanting to take time off for vacation or to study, to be contracted by AHP for 6 months to work partly for GPs and partly (when no GP needs a locum) in district hospitals.

The GP will pay the locum to run their practice and do their sessions. When there is no locum work, the doctor will work at a district hospital at a normal Eastern Cape Province rate for a Senior Medical Officer. The amount of thought that has gone into the planning displays a deep knowledge of the often chaotic situation on the ground and is informed by interviews in June 2009 with 37 doctors (mostly sessional) and 16 hospital managers in 2 rural districts. One paragraph in the Outline and Implementation Draft Plan drawn up last October is revealing: 'If the red tape at Bhisho (Head Office) is such that it is too difficult for the province to pay a doctor working intermittently at different district hospitals, the AHP undertakes to pay them from the project budget'.

This will be reviewed during the first year to see if the locum system works and if a mechanism can be found for the Eastern Cape Department of Health to pay when the doctor is working for them.

Which, it would seem, handsomely illustrates the entire raison d'être of the project.

Wilson said that, while no 'silver bullet', the project could well be tailored to the specific needs of struggling health districts in other provinces after similar consultative groundwork. This would depend on further seed-funding successes.

\section{Chris Bateman}

